Check for updates

Cite this: Mater. Adv., 2020, 1,3378

Received 14th July 2020,

Accepted 4th October 2020

DOI: $10.1039 / \mathrm{d} 0 \mathrm{ma00507j}$

rsc.li/materials-advances

\section{Novel approaches in the use of polyacrylate ester- based polycarboxylates (PCEs) as leather retanning agents}

\author{
Miquel Canudas, (D) *ab Nicola Menna, ${ }^{b}$ Antoni Torrelles, $\dagger^{b}$ Joan de Pablo ${ }^{a}$ and \\ Josep Maria Morera (iD ${ }^{c}$
}

\begin{abstract}
Retanning is one of the main stages for leather manufacturing. Linear anionic polyacrylates are widely used as retanning agents to minimize the use of phenolic and sulfone syntans, which are less environmentally friendly polymers. Nevertheless, their use as anionic retanning agents reduces the cationic charge of chrome tanned leathers, which influences the following stages: dyeing and fatliquoring. As a result, leathers with low dye uniformity, low colour intensity and rough grain are obtained. Polyacrylate ester-based polycarboxylates can be alternative retanning agents that do not cause these deficiencies in the dyeing and fatliquoring stages. However, the effects of their chemical structure on the final leather properties are not well understood yet. In this study, an attempt has been made to analyze the influence of the molecular weight of the PCE polyalcohol side chains in the final properties of retanned leather. PCEs with polyalcohol side chains of different molecular weights were synthesized, characterised and subjected to a biodegradability test. Retanning tests using PCEs were carried out in comparison to a commercial linear anionic polyacrylate. Different physical properties of the retanned leathers were analyzed. The internal collagen structure of the retanned leather was evaluated by scanning electron microscopy (SEM). The results revealed that PCEs with low molecular weight polyalcohol side chains were able to solve the problems of linear polyacrylates in dyeing and fatliquoring stages and improve the final leather softness, colour intensity and physical properties. This study proves that PCEs with low molecular weight polyalcohol side chains can act as a good biodegradable alternative to linear anionic polyacrylates as retanning agents.
\end{abstract}

\section{Introduction}

Leather is a natural fibrous material by-product of the meat industry. ${ }^{1-4}$ Fibrillar type I collagen is its main structural component and, due to its complex hierarchical structure, it is responsible for the mechanical properties and functionality of leather. ${ }^{5,6}$ Due to the different stages of the leather making process (preservation, beamhouse, tanning, retanning, dyeing, fatliquoring and finishing), the collagen structure is modified and reacts with multiple chemicals. ${ }^{7}$ Its final degree of crosslinking, hierarchical structure and mechanical properties will define the specific characteristics of the final leather product. $^{8-12}$

Nowadays, retanning has become an important stage in the leather manufacturing process. It contributes to the structural

\footnotetext{
${ }^{a}$ Chemical Engineering Department, Universitat Politècnica de Catalunya (UPC), Av. d'Eduard Maristany, 10-14, 08930 Barcelona, Spain

${ }^{b} R \& D$ Department, Cromogenia Units S.A., Carrer 42 Polígon Industrial Zona

Franca, 2-10, 08040 Barcelona, Spain

${ }^{c}$ Department of Computer Science and Industrial Engineering, Universitat de Lleida (UdL), Av. Pla de la Massa, 8, 08700 Igualada, Spain

$\dagger$ Deceased.
}

modification and stabilization of collagen fibres and it gives specific characteristics to the final leather (selective filling of the structure, tight and uniform grain surface, elasticity, etc. $).{ }^{13-15}$ Retanning is also a key stage for leather reactivity in the subsequent dyeing and fatliquoring stages. ${ }^{1}$ A wide variety of chemicals are used as retanning agents, such as inorganic mineral substances (chrome, aluminium and zirconium salts), natural modified organic products (tara tannins, mimosa tannins, chestnut tannins, lignosulfonates, etc.) and synthetic organic agents (aldehydes, phenolic polymers, naphthalenic polymers, sulfone polymers, melamine resins, dicyandiamide resins, ureaformaldehyde resins, etc.). ${ }^{1}$ Depending on the requested final leather characteristics, one product or another, or a combination of them, will be used. ${ }^{13-17}$

To minimize the use of classic retanning agents that are not particularly environmentally friendly products, linear polyacrylic polymers have recently become more important because of their chemical characteristics and environmental benefits. ${ }^{17-19}$ They are based on linear homopolymers or copolymers of acrylic acid and its derivatives synthesized by free radical polymerization. ${ }^{20-22}$ Their structure, with abundant carboxyl side groups, gives them 
a high anionic charge, which makes them ideal to react via hydrogen and/or ionic bonds with chrome tanned cationic leathers. $^{23-27}$ However, this reaction causes a change in the leather's charge density, leading to negative effects on the dyeing and fatliquoring stages. Low cationic leathers do not have strong affinity for dyes and fatliquors, which are usually anionic products, and the result is the obtention of rough grain leathers with low softness, low colour intensity and low dye uniformity. ${ }^{17,25-28}$ To prevent the loss of leather properties, the leather industry uses a mix of retanning agents that combines linear polyacrylates with chrome(III) salts or synthetic organic agents. ${ }^{1}$

This combination of retanning agents reduces the environmental benefits of the acrylic polymers. Some constituents of the synthetic organic agents such as phenol, formaldehyde and naphthalene pose significant risks to the environment and health. ${ }^{29-32}$ Moreover, chrome(III) salts used in the retanning process are not completely fixed on the leather and free chrome(III) can be oxidized under certain conditions that can occur during the retanning process to chrome(vi), which is a restricted substance because of its toxicity and carcinogenicity. ${ }^{22,33-36}$

The increasing environmental and health pressures in the leather industry have led to the study of alternative retanning agents instead of linear polyacrylates. ${ }^{36}$ A possible group of candidates suggested in the literature are polyacrylate esterbased polycarboxylates (PCEs). ${ }^{37}$

PCEs consist of one main polyacrylic anionic chain (backbone chain) with some of its carboxyl groups esterified with polyalcohol units (uncharged side chains). ${ }^{38-42}$ Due to the ratio between the backbone and the side chain length, PCEs have been reported to show comb-shaped, worm-shaped or even star-shaped molecular architecture structures. ${ }^{41-43}$ Their conformation represents an important property for their interaction with leathers. ${ }^{43-45}$ An important trait of this type of product is that their chemical structure (backbone chain and side chains) has the potential to be modified, from the point of view of molecular weight, monomer composition and the chemical nature of the side chains, depending on their final use. ${ }^{46-51}$

The use of PCEs as retanning agents without synthetic organic agents or chrome(III) salts seems to lead to leathers with higher softness and colour intensity, avoiding the problems of the linear polyacrylic retanning agents during the dyeing and fatliquoring stages. ${ }^{37}$ However, their effect on the final physical leather properties are not well understood yet.

Hence, this study aims to analyse the influence of the molecular weight of polyalcohol side chains on the final leather internal collagen structure and physical properties, giving information of the biodegradability of the PCE products.

\section{Experimental}

\subsection{Materials and chemicals}

Split chrome tanned sheepskins from France shaved at $1.1 \mathrm{~mm}$ were chosen as the raw material for the retanning test study.

Four synthesized PCE polymers were used for the study as retanning agents. For the synthesis of these polymers, commercial acrylic acid was used to synthesize the polyacrylic backbone chain with a molecular weight $\left(M_{\mathrm{w}}\right)$ of $13650 \mathrm{~g} \mathrm{~mol}{ }^{-1}$, which was esterified with a specific molecular weight commercial polyalcohol chain $\left(1000 \mathrm{~g} \mathrm{~mol}^{-1}, 2000 \mathrm{~g} \mathrm{~mol}^{-1}, 3000 \mathrm{~g} \mathrm{~mol}^{-1}\right.$ and $5000 \mathrm{~g} \mathrm{~mol}^{-1}$ ).

Linear polyacrylic polymer (AR) with a molecular weight of $615000 \mathrm{~g} \mathrm{~mol}^{-1}$ produced by Cromogenia Units was used as a standard retanning agent to compare with the synthesized PCE polymers. AR was chosen because of its high molecular weight and its good performance as a commercial retanning agent compared to other acrylic polymers on the market. The leather industry has proved that high molecular weight acrylic resins have better leather fixation and higher filling effects compared to those of low molecular weight. ${ }^{52}$

The other chemicals used for the retanning tests were of commercial grade: basic chromium(III) sulfate with a basicity of $33 \%$ with a content of $25 \%$ in $\mathrm{Cr}_{2} \mathrm{O}_{3}$, an anionic dyestuff (colour index Acid Brown 83), a sulphated neatsfoot oil (75\% of active matter) and a sulfochlorinated paraffin ( $67 \%$ of active matter). The chemicals used in the operations before and after retanning were chemicals commonly used in the tanning industry.

\subsection{Equipment}

The synthesis process was performed in a $2 \mathrm{~kg}$ laboratory Schott Duran glass reactor equipped with an anchor stirrer, a vapour condenser and a temperature sensor with an automatic controller. It was also connected to a peristaltic pump to control the addition fluxes.

Retanning tests were carried out in Simplex DF-2 Inoxvic drums of $50 \mathrm{~cm}$ width and $100 \mathrm{~cm}$ diameter and equipped with speed and temperature regulators.

\subsection{Synthesis of the PCEs}

The synthesis procedure was divided into two steps (Scheme 1): backbone chain synthesis, which was based on free radical

Free radical polymerization

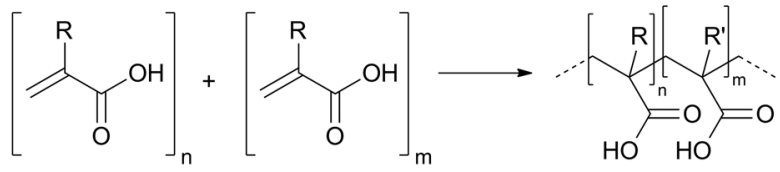

Acrylic derivative monomers

Backbone chain

Esterification reaction:

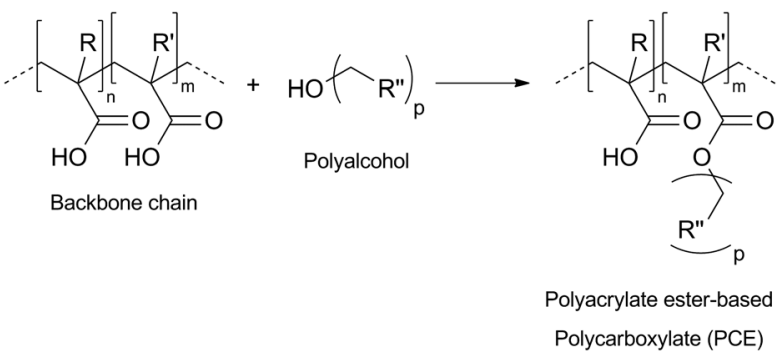

Scheme 1 Synthesis of polyacrylate ester-based polycarboxylate. ${ }^{37}$ 
polymerization of the acrylic acid; and addition of side chains, which was carried out by selective Fischer's esterification of a polyalcohol chain at some of the backbone's carboxyl groups.

\subsection{Characterization}

PCE free monomer was determined by performing gas chromatography-mass spectrometry (GC-MS) measurements using a Hewlett Packard HP 6890 Series chromatographic apparatus equipped with a HP-5MS Capillary column (30.0 $\mathrm{m} \times$ $250 \mu \mathrm{m} \times 0.25 \mu \mathrm{m}$ ), an Agilent 7694E Head Space and a 5973 Mass Selective detector. The samples were analysed using the following chromatographic conditions: helium as the carrier gas at a flow rate of $1 \mathrm{~mL} \mathrm{~min}{ }^{-1}$, injector temperature of $280{ }^{\circ} \mathrm{C}, 1 \mathrm{~mL}$ split injection, split ratio of $50 / 1$, oven temperature program of $60^{\circ} \mathrm{C}$ for $5 \mathrm{~min}$ and then ramp at $10{ }^{\circ} \mathrm{C} \mathrm{min}^{-1}$ to $200{ }^{\circ} \mathrm{C}$, MS Source temperature of $230{ }^{\circ} \mathrm{C}$, MS Quad temperature of $150{ }^{\circ} \mathrm{C}$ and head space line temperature of $115{ }^{\circ} \mathrm{C}$.

The average molecular weight was determined by size exclusion chromatography (SEC) measurements using an Agilent 1260 Infinity chromatographic instrument equipped with three ultrahydrogel Waters columns (ultrahydrogel 120, 250 and 500) and an IR detector. The samples were analysed using $0.1 \mathrm{~mol} \mathrm{~L}^{-1}$ sodium nitrate aqueous solution as an eluent at $45{ }^{\circ} \mathrm{C}$ and a

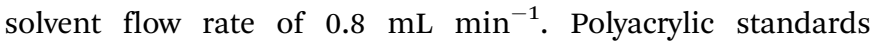
$\left(1930 \mathrm{~g} \mathrm{~mol}^{-1}, 3800 \mathrm{~g} \mathrm{~mol}^{-1}, 8300 \mathrm{~g} \mathrm{~mol}^{-1}, 18100 \mathrm{~g} \mathrm{~mol}^{-1}\right.$ and $37100 \mathrm{~g} \mathrm{~mol}^{-1}$ ) were used for calibration.

Infrared spectra (IR) were recorded using a Nicolet i510 spectrophotometer. Liquid samples were prepared by creating a film on two $\mathrm{KBr}$ plates. The spectra were taken at a resolution of $4 \mathrm{~cm}^{-1}$ with 4 scans averaged from 4000 to $400 \mathrm{~cm}^{-1}$.

\subsection{Retanning process}

To avoid the anisotropic effect, retanning tests were carried out by splitting sheepskins through the backbone. Hence, the PCE test was performed on the right side and the standard test with AR was performed on the left side. Both products (PCE and AR) were applied at $5 \%$ active matter following the retanning recipe listed in Table 1.

\subsection{Leather characterization - organoleptic tests}

All the retanned leathers obtained were checked using organoleptic tests carried out by four independent experts of the leather industry. The evaluated properties were fullness, visual colour levelness, visual colour intensity, grain tightness and superficial touch. Typical leather industry organoleptic test classification goes from 1 (the worst value) to 5 (the best value).

\subsection{Leather characterization - physical properties}

Leather physical properties were evaluated following IUP (physical test methods) standard leather rules defined by the International Union of Leather Technologist and Chemists Society (IULTCS). These rules have an equivalence concerning the International Organization for Standardization rules (ISO)..$^{53}$

Before acquiring the measures, leather samples were cut from the official sampling position and conditioned for $48 \mathrm{~h}$ at
Table 1 Retanning recipe for leather tests

\begin{tabular}{|c|c|c|c|c|c|}
\hline Process & Chemicals & $\%$ & $\begin{array}{l}\text { Time } \\
\text { (min) }\end{array}$ & $\begin{array}{l}T \\
\left({ }^{\circ} \mathrm{C}\right)\end{array}$ & $\mathrm{pH}$ \\
\hline \multirow[t]{3}{*}{ Washing } & Water & 200 & 30 & 35 & 3.5 \\
\hline & Non-ionic surfactant & 0.2 & & & \\
\hline & Formic acid & 0.2 & & & \\
\hline \multicolumn{6}{|l|}{ Drain } \\
\hline \multirow[t]{3}{*}{ Rechroming } & Water & 100 & & 35 & 4.1 \\
\hline & Basic chromium(III) sulfate & 5 & 30 & & \\
\hline & Sodium formate & 1.5 & 30 & & \\
\hline \multicolumn{6}{|c|}{ Overnight. Drain and rinse } \\
\hline \multirow[t]{3}{*}{ Neutralization } & Water & 150 & & 30 & 5.0 \\
\hline & Sodium formate & 2 & 15 & & \\
\hline & Sodium bicarbonate & 0.5 & 60 & & \\
\hline \multicolumn{6}{|c|}{ Drain and rinse } \\
\hline \multirow[t]{2}{*}{ Retanning } & Water & 50 & & 35 & \\
\hline & $\begin{array}{l}\text { Retanning agent } \\
\text { (5\% of active matter) }\end{array}$ & 5 & 60 & & \\
\hline \multirow[t]{2}{*}{ Dyeing } & Dispersing agent & 2 & & & \\
\hline & Dyestuff & 2 & 45 & & \\
\hline \multirow[t]{4}{*}{ Fatliquoring } & Water & 50 & & 50 & 3.7 \\
\hline & Sulphated neatsfoot oil & 5 & 60 & & \\
\hline & Sulfochlorinated paraffin & 5 & & & \\
\hline & Formic acid & 2 & 60 & & \\
\hline
\end{tabular}

$20 \pm 2{ }^{\circ} \mathrm{C}$ and $65 \%$ relative humidity following the rules IUP $1-$ IUP 3 (ISO 2419:2012) and IUP 2 (ISO 2418:2017).

All physical properties were evaluated as per standard procedures: ${ }^{54}$

- Softness degree according to IUP 36 (ISO 17 235:2015) using a Softness Tester.

- Thickness value according to IUP 4 (ISO 2589:2016) using a thickness gauge.

- Colour intensity using a Ci7600 X-Rite spectrophotometer based on the chromatic model CIELAB for colour measures.

- Tensile strength and percentage elongation according to IUP 6 (ISO 3376:2011) using a Zwick TMZ2.5/TN1S instrument.

- Tear load according to IUP 8 (ISO 3377-2:2016) using a Zwick TMZ2.5/TN1S instrument.

- Distension and grain crack strength according to IUP 9 (ISO 3379:2015) using a Satra STM 463 Digital Lastometer.

- Absorption drop time according to an internal rule. A drop of water was placed on the grain surface and the time it took to be absorbed by the leather was measured.

The value reported for each property is an average of four measurements (two along and two across the sheepskin backbone).

\subsection{Leather characterization - scanning electron microscopy}

The internal retanned leather collagen structure was analysed using scanning electron microscopy (SEM). Leather samples were cut from the official sampling position according to IUP 2 (ISO 2418:2017). These samples were cut into specimens with a uniform thickness. All specimens were painted with silver paint and coated with carbon using an Emitech K950X carbon coater. A Phenom XL desktop scanning electron microscope was used to get the micrographs of the retanned leather grain surface and the retanned leather cross section by operating the SEM at 
medium vacuum with an accelerating voltage of $10 \mathrm{kV}$ at different magnification levels.

\section{Results and discussion}

\subsection{PCE characterization}

The European regulation on classification, labelling and packaging of substances and mixtures (CLP Regulation) indicates that hazardous products must be labelled with pictograms. ${ }^{54}$ In this case, PCE free monomer values obtained were less than $0.2 \%$, which means very optimal polymerization reaction conditions.

The average molecular weight $\left(M_{\mathrm{w}}\right)$, the number average molecular weight $\left(M_{\mathrm{n}}\right)$ and the polydispersity index (PDI) measured for all the synthesized PCEs are given in Table 2.

PDI describes the uniformity of a polymer compared to the molecular mass distribution, which indicates the number of molecular weight populations of the polymer. If the PDI value is 1 , the polymer would have one population with only one molecular length. Hence, a lower PDI value obtained for a PCE indicates that the polymer chain population possesses a similar molecular weight.

The synthesized PCE products were analysed by IR spectroscopy in order to identify the functional groups that characterise these products in terms of structure. Fig. 1 shows the IR spectrum for PCE1000, which is very similar to those of the other PCEs because its chemical structure contains the same functional groups. Some PCE characteristic peaks are the ester carbonyl absorption peak at $1750 \mathrm{~cm}^{-1}(\mathrm{C}=\mathrm{O}$ stretching vibrations) created during the esterification reaction and the hydroxyl peak of the backbone-free carboxylic groups at 3400$3650 \mathrm{~cm}^{-1}$ (-OH and $-\mathrm{COOH}$ stretching vibrations). The peak at $2800-3000 \mathrm{~cm}^{-1}$ is due to stretching of the carbon-hydrogen bond in the methyl groups and the peak at $1100-1200 \mathrm{~cm}^{-1}$ corresponds to $\mathrm{C}-\mathrm{O}-\mathrm{C}$ stretching.

\subsection{Biodegradability test}

Biodegradability tests for PCE1000 and AR were performed following the OCDE $301 \mathrm{~F}$ rule using a Challenge AER-800 closed automatic respirometer. ${ }^{55}$ The data recorded for a period of

Table 2 SEC values for the different synthesized PCEs

\begin{tabular}{lcll}
\hline Polymer & $M_{\mathrm{w}}\left[\mathrm{g} \mathrm{mol}^{-1}\right]$ & $M_{\mathrm{n}}\left[\mathrm{g} \mathrm{mol}^{-1}\right]$ & PDI \\
\hline PCE1000 & 35044 & 14017 & 2.5 \\
PCE2000 & 64499 & 22241 & 2.9 \\
PCE3000 & 129687 & 40527 & 3.2 \\
PCE5000 & 198147 & 70766 & 2.8
\end{tabular}

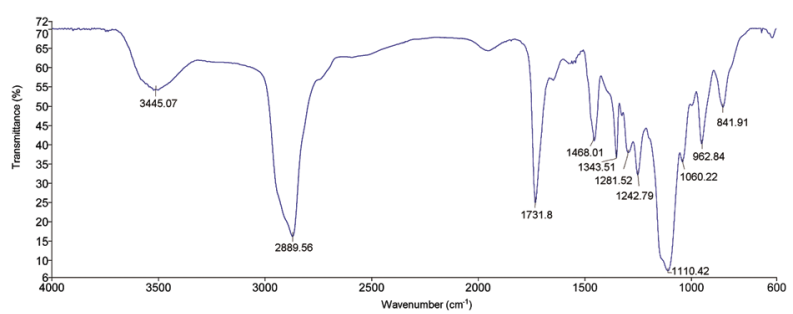

Fig. 1 IR Spectrum of PCE1000.

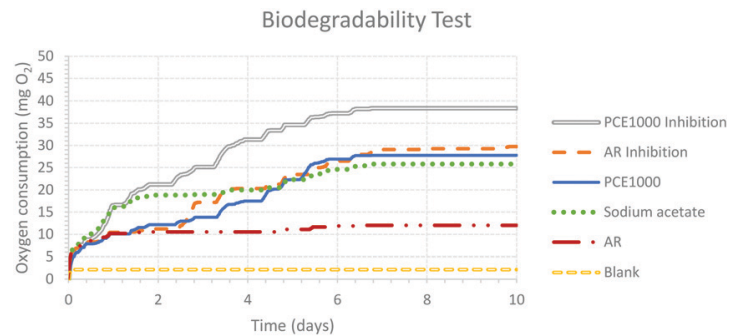

Fig. 2 Biodegradability test. Ratio of oxygen consumption versus time.

Table 3 ThOD and COD values for PCE1000 and AR

\begin{tabular}{lllc}
\hline & $\begin{array}{l}\text { ThOD } \\
{\left[\mathrm{mgO}_{2} \mathrm{mg}^{-1}\right]}\end{array}$ & $\begin{array}{l}\text { Inoculated } \\
\text { ThOD }\left[\mathrm{mgO}_{2} \mathrm{~L}^{-1}\right]\end{array}$ & $\begin{array}{l}\mathrm{COD} \\
{\left[\mathrm{mgO}_{2} \mathrm{~L}^{-1}\right]}\end{array}$ \\
\hline PCE1000 & 414 & 241.6 & 54 \\
AR & 848 & 118 & 100
\end{tabular}

10 days are graphically based on the ratio of oxygen consumption versus time (Fig. 2).

A correct trend of biodegradation can be observed in the acquired data. Oxygen consumption curves evolve progressively towards a constant maximum in time and the profile of each curve indicates that all samples evolve following the expected behaviour.

Blank's oxygen consumption is low, which is expected since it corresponds to the endogenous activity of the inoculum (basal respiration of the sludge). Sodium acetate, which is the reference sample of known biodegradability, shows rapid biodegradation. For the two inhibition samples, the recorded oxygen consumption presents the same trend as the reference sample, which means that there is no inhibition and consequently neither of the two products under study (PCE1000; $\mathrm{AR}$ ) are toxic for the microorganisms of the mud.

Comparing the profile curves of PCE1000 and AR, it is clear that oxygen consumption is significantly higher for PCE1000. Hence, it can be qualitatively considered that PCE1000 shows a higher biodegradability than AR.

At the end of the biodegradability test, COD was analysed in the inoculated mineral media (Table 3 ). Biodegradability values are obtained with the final media COD values and the initial inoculated ThOD values following the equation: ${ }^{53}$

$$
\% \text { bio degradability }=\frac{\text { ThOD }- \text { COD }}{\text { ThOD }} \times 100
$$

A value of $78 \%$ biodegradability was obtained for PCE1000 and a value of $15 \%$ was obtained for AR. These numbers confirm the qualitative behaviour and the higher biodegradability of PCE1000 than AR.

\subsection{Organoleptic properties of the retanned leathers}

In order to verify the good performance of the retanning tests and the retanned leather's final quality, an organoleptic assessment was made by four independent leather industry experts and the data are presented in Table 4 using the leather organoleptic classification of 1 (worst value) to 5 (best value). 
Table 4 Organoleptic properties of the retanned leathers

\begin{tabular}{llllll}
\hline & & $\begin{array}{l}\text { Visual } \\
\text { colour } \\
\text { levelness }\end{array}$ & $\begin{array}{l}\text { Colour } \\
\text { intensity }\end{array}$ & $\begin{array}{l}\text { Grain } \\
\text { tightness }\end{array}$ & Superficial touch \\
\hline PCE1000 & 5 & 5 & 5 & 5 & 5 (soft and silky) \\
PCE2000 & 3 & 4 & 4 & 4 & 4 (soft) \\
PCE3000 & 1 & 4 & 4 & 1 & 1 (very hard) \\
PCE5000 & 1 & 4 & 4 & 1 & 1 (very hard) \\
$\operatorname{AR}^{a}$ & 5 & 1 & 1 & 5 & 2 (hard and dry)
\end{tabular}

${ }^{a}$ The results obtained for the four AR controls were the same.

Organoleptically, PCE1000 retanned leather was the best one according to the expert's assessment whereas PCE2000 retanned leather was found to be emptier.

PCE1000 retanned leather was a full, soft and silky to the touch leather with the highest colour intensity, levelness and uniformity. On the other hand, PCE3000 and PCE5000 retanned leathers were the hardest and emptiest ones. Their stiff look means that the chemicals underwent a bad interaction with the leather's collagen matrix and, consequently, they are not suitable retanning agents.

Visual colour levelness and colour intensity are related to the ionic charge of polymers. Unlike AR, all the PCE retanned leathers show high values for the two properties. PCEs have a lower anionic charge compared to AR. Hence, their interaction with leather leaves a more cationic surface than AR. The more cationic the surface becomes after retanning, the more dyes and fatliquors, which are products with anionic charge, can be fixed in the leather.

Fullness, grain tightness and superficial touch are related to the retanning agents' structural properties like molecular weight and 3D architecture. In the literature, there are several studies that report that PCEs show a different architecture structure (comb-shaped, brush or worm-shaped and star-shaped) as a function of their ratio between the backbone chain and the side

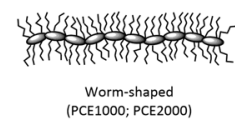

Worm-shaped
(PCE1000; PCE2000)

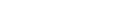

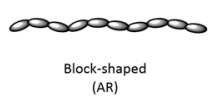

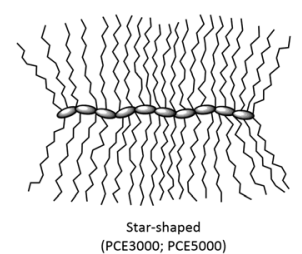

Star-shaped
(PCE3000; PCE5000)
Fig. 3 Schematic representation of the molecular architecture proposed for PCEs and AR. ${ }^{43-45}$ polyalcohol chain length. ${ }^{43-45}$ Fig. 3 shows a schematic representation of the possible molecular architecture proposed for the different synthesized PCEs. PCE1000 and PCE2000 have shorter grafted side chains and, with the organoleptic assessment results, this suggests that they are worm-shaped polymers. PCE3000 and PCE5000, on the other hand, have longer side polyalcohol chains and, considering the organoleptic results, they probably have a star-shaped molecular architecture. It should be mentioned that AR, as a linear polyacrylic polymer, shows a block-shaped architecture structure.

Considering the organoleptic assessment, it can be determined that polymers with lower molecular weight polyalcohol side chains (PCE1000 and PCE2000) show better results for fullness, grain tightness and superficial touch than those with higher molecular weight side chains (PCE3000 and PCE5000). Hence, polymers with lower molecular weight polyalcohol side chains form a better packing in aqueous medium, which allows them to achieve better penetration in the interstices of the collagen matrix in leather. In contrast to the PCEs' behaviour, leathers retanned with AR have high values of fullness and grain tightness despite its high molecular weight. These high values can be explained by AR's linear and non-branched structure, which allows it to achieve high penetration, similar to that of PCE1000 and PCE2000.

However, leathers retanned with AR show a lower superficial touch rating in comparison to PCE1000 and PCE2000, which means that at an equal penetration of the retanning agent, the presence of polyalcohol chains in PCEs improves the property of superficial touch significantly. Hence, it can be determined that the property of superficial touch is influenced by a synergy between the molecular weight of the polymers, their chemical nature and the $3 \mathrm{D}$ structure.

\subsection{Physical properties of the retanned leathers}

The values for each physical property for PCE1000, PCE2000 and AR retanned leathers are given in Table 5.

The obtained lightness values confirm that PCEs as retanning agents generate leathers with higher colour intensity than AR (Fig. 4). Because of the carboxyl esterified groups, PCE molecules have a lower anionic charge in comparison to linear polyacrylic polymers. Hence, PCE molecules leave more free cationic points on the leather surface after retanning, so the leather traps more anionic dye. The difference in colour intensities between PCE1000 and PCE2000 is related to their molecular weight. The higher molecular weight of PCE2000 does not allow

Table 5 Physical property values for the retanned leathers

\begin{tabular}{|c|c|c|c|c|c|c|c|c|c|}
\hline & \multirow{2}{*}{$\begin{array}{l}\text { Colour } \\
\text { intensity }\left(\mathrm{L}^{*}\right)\end{array}$} & \multirow{2}{*}{$\begin{array}{l}\text { Thickness } \\
{[\mathrm{mm}]}\end{array}$} & \multirow[b]{2}{*}{ Softness } & \multirow{2}{*}{$\begin{array}{l}\text { Absorption } \\
\text { drop time }[\mathrm{s}]\end{array}$} & \multirow{2}{*}{$\begin{array}{l}\text { Tensile } \\
\text { strength }[\mathrm{MPa}]\end{array}$} & \multirow{2}{*}{$\begin{array}{l}\text { Elongation } \\
{[\%]}\end{array}$} & \multirow{2}{*}{$\begin{array}{l}\text { Tear load } \\
{[\mathrm{N}]}\end{array}$} & \multicolumn{2}{|c|}{ Grain crack strength } \\
\hline & & & & & & & & Distension $[\mathrm{mm}]$ & Load $[\mathrm{kg}]$ \\
\hline PCE1000 & $55.2 \pm 1.1$ & $1.1 \pm 1.0$ & $5.1 \pm 0.2$ & $19.1 \pm 0.4$ & $44.0 \pm 3.5$ & $24.1 \pm 4.3$ & $67.9 \pm 2.7$ & $11.1 \pm 0.6$ & $60.8 \pm 3.0$ \\
\hline $\mathrm{AR}$ & $67.1 \pm 1.3$ & $1.2 \pm 1.0$ & $4.2 \pm 0.2$ & $4.2 \pm 0.1$ & $26.8 \pm 2.2$ & $12.5 \pm 2.3$ & $44.1 \pm 1.8$ & $9.8 \pm 0.4$ & $40.2 \pm 2.0$ \\
\hline Variation & $17.7 \%$ & $8.3 \%$ & $21.4 \%$ & $354.8 \%$ & $69.1 \%$ & $92.3 \%$ & $54.1 \%$ & $12.8 \%$ & $51.5 \%$ \\
\hline PCE2000 & $58.6 \pm 1.2$ & $0.8 \pm 1.0$ & $5.0 \pm 0.2$ & $22.2 \pm 0.4$ & $42.9 \pm 3.4$ & $18.8 \pm 3.4$ & $59.4 \pm 2.4$ & $11.7 \pm 0.6$ & $48.5 \pm 2.4$ \\
\hline $\mathrm{AR}$ & $64.1 \pm 1.3$ & $1.3 \pm 1.0$ & $4.6 \pm 0.2$ & $8.0 \pm 0.2$ & $24.5 \pm 1.9$ & $7.9 \pm 1.4$ & $38.5 \pm 1.5$ & $10.1 \pm 0.5$ & $30.5 \pm 1.5$ \\
\hline Variation & $8.6 \%$ & $38.5 \%$ & $8.7 \%$ & $177.5 \%$ & $74.9 \%$ & $98.8 \%$ & $54.5 \%$ & $15.6 \%$ & $58.9 \%$ \\
\hline
\end{tabular}




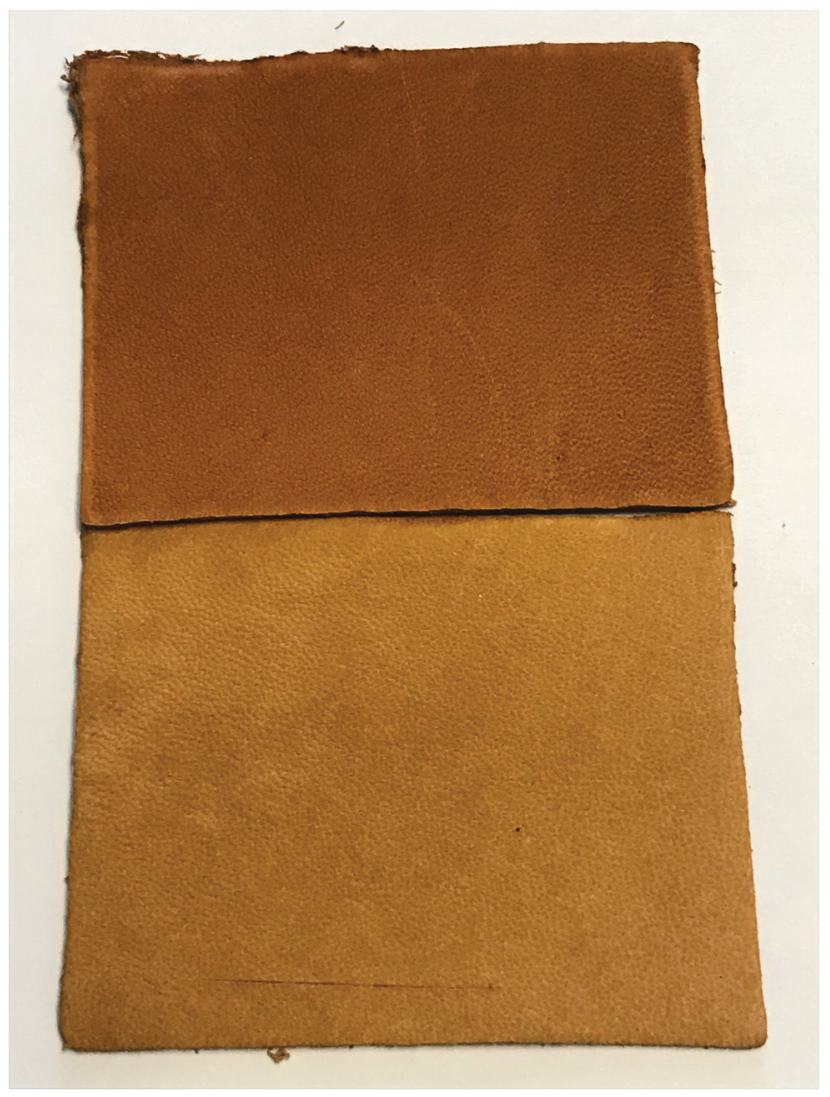

Fig. 4 Surface colour intensity for pieces retanned with PCE1000 (above) and AR (below).

the molecule to penetrate deeper inside the leather and, consequently, it remains deposited in the leather surface, blocking cationic sites that could interact with dyes.

Similar thickness values were obtained for PCE1000 and AR. It is well known that the retanning effectiveness of linear polyacrylate polymers is related to their depth penetration and filling ability in leather. Literature studies have demonstrated that with a higher linear polyacrylate molecular weight, larger gaps between collagen fibres could be filled, which means an increase in the leather thickness. ${ }^{52}$ This is the main reason why AR, which has a high molecular weight, was chosen as a linear polyacrylate standard. The AR leather's thickness value obtained during the retanning tests corroborated the literature reasoning. However, the thickness values of leathers retanned with PCEs indicate that their way of acting on the leather thickness is the opposite. PCEs with lower molecular weight polyalcohol side chains had a better filling effect and higher thickness values. This trend can be observed by comparing the thickness values for PCE1000 and PCE2000. In the case of PCE1000, because of its 3D packing, more polymer molecules enter inside the leather, which increases the thickness.

Meanwhile, polymers with higher molecular weight polyalcohol side chains form worse packing, causing fewer polymer molecules to fill the interstices of the leather.

Other physical properties such as softness, tensile strength, percentage of elongation, tear load or strength of grain show similar results for PCE1000 and PCE2000 retanned leathers, but they are better than those of leather retanned with AR. These values indicate that PCE retanned leathers are more flexible and dissipate more energy before cracking the leather grain or breaking the collagen fibres. The ionic PCEs' charge and their polyalcohol side chains are responsible for these property improvements.

On one hand, the low anionic charge allows PCE retanned leathers to fix more content of fatliquors, providing a layer of lubrication to the collagen fibres. The lubrication of the collagen fibres dehydrated during the tanning and retanning stages is essential to allow them to separate and slide over each other, which is the key property for obtaining leathers with higher flexibility, softness and resistance to different applied forces. On the other hand, the polyalcohol nature of the PCE side chains can contribute to an extra hydration of the collagen fibres, which also prevents dimensional shrinkage during drying, retaining moisture in the collagen structure. This humectant and moisturizing effect of the polyalcohol chains has been corroborated in other studies. ${ }^{6,56-60}$

The absorption drop time gives information about the retanned leather waterproofness. It is noted that higher values were obtained for the PCE retanned leathers in comparison to the AR ones. These values can be explained in terms of hydrophobicity. Because of their low anionic charge, PCE retanned leathers can fix more fatliquors than AR, which also increases the hydrophobicity of the final leather. The best results for PCE1000 retanned leather compared to PCE2000 are due to the lower molecular weight of the polyalcohol side chains, which favours the packing of the polymer molecules inside the leather.

\subsection{Characterization of the retanned leather collagen by SEM}

To characterise the internal collagen structure of the PCE1000 and AR retanned leathers, SEM analysis was performed to deeply observe effects on leather fibres and grain structure. Observations at different magnifications were done at different points of the grain surface and a cross-section of the retanned leathers was obtained.

SEM micrographs of the retanned leather's grain surface are shown in Fig. 5 with a magnification of $250 \times$. Upon comparing the images, no significant structural differences are observed. Both of them exhibit a clear grain surface, which indicates that
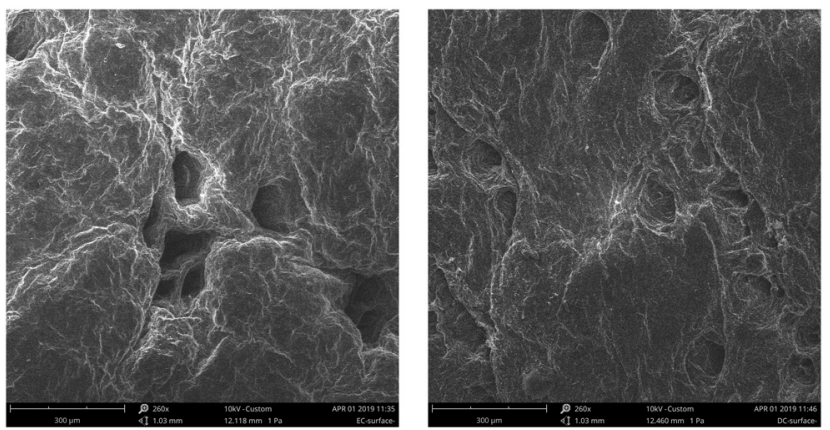

Fig. 5 SEM micrographs of the retanned leather grain surface at $260 \times$ (PCE1000 retanned leather on the left and AR retanned leather on the right). 
there is no physical deposition. Hair follicles look clean without any foreign materials in all cases.

The cross-sectional view of the retanned leathers at different magnifications is shown in the SEM micrographs in Fig. 6.

SEM micrographs of PCE1000 retanned leather show a higher degree of internal fibre organization with undamaged, defined, thick and entire fibre bundles, whereas the SEM micrographs for AR retanned leather show a messy fibre organization with fine fibre splitting. Moreover, PCE1000 retanned leather does not show cavities and presents a more compact fibre structure than AR retanned leather.

These SEM micrograph results complement the previous arguments used to explain the improvement of physical properties of the PCE retanned leathers compared to those of the AR retanned leathers. High fibril orientation in retanned leathers is normally associated with high strength and compactness in the fibre structure throughout the cross-section, which indicates uniform filling of the retanning agents.

The high internal fibre organization of PCE1000 retanned leather facilitates fibre orientation in the direction of the applied force, which, at the same time, allows them to dissipate the energy, preventing a premature mechanical failure. On the other hand, deficiencies in the structural organization of AR retanned leathers cause a faster fibre crack and rupture.

The internal fibre organization and the compact structure of the PCE1000 retanned leather may be explained by the humectant and moisturizing effect of the polyalcohol side chains, the 3D structure of the PCE molecule and its total ionic charge. Polyalcohol side chains coat the collagen fibres,
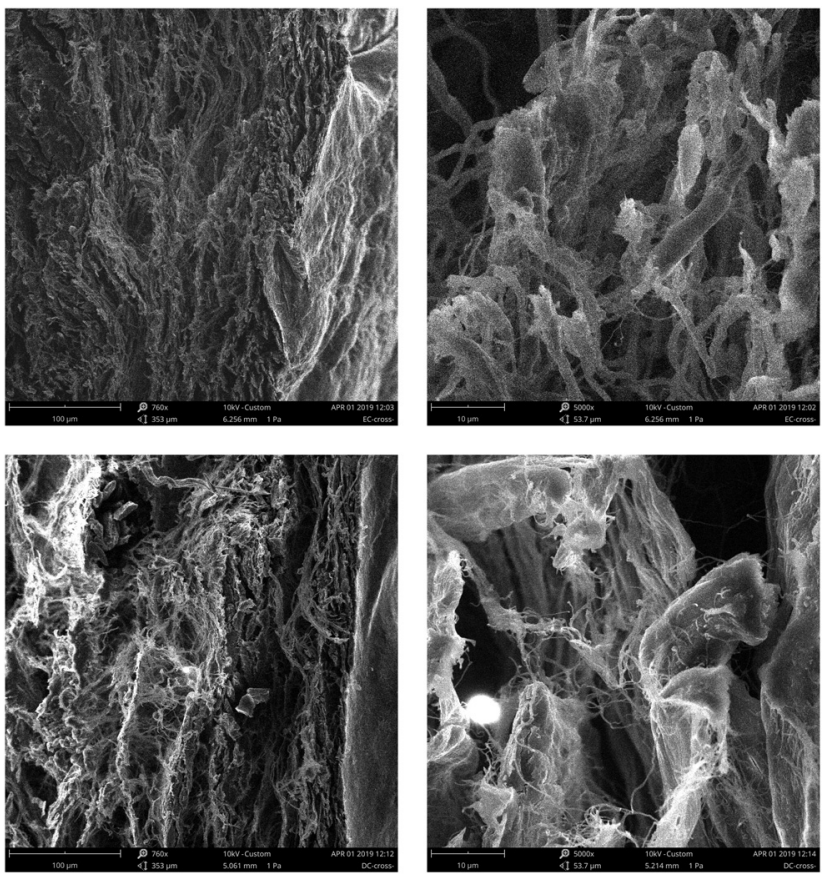

Fig. 6 SEM micrographs of the retanned leather cross-sections at $760 \times$ on the left and fibre bundles of those leathers at $5000 \times$ on the right. Micrographs of PCE1000 retanned leather are the two above and those for AR retanned leather are the two below. keeping their water, which allows the fibres to slip over each other. The total ionic charge, which is less anionic than AR, increases the fixation of fatliquors that lubricate the collagen fibres, protecting them to avoid defibrillation. The worm-shaped structure allows the deposition of the PCE1000 molecule inside the retanned leather, filling the cavities and creating a more compact structure.

\section{Conclusions}

New leather industry regulations on environment protection have caused an increase in the use of linear polyacrylic polymers as retanning agents to reduce the consumption of classical retanning agents based on phenol, formaldehyde, naphthalene and chrome(III). However, these classical products continue to be used to avoid the problems caused by the linear polyacrylic polymers in the dyeing and fatliquoring stages. The synthesis of PCEs as alternatives to linear polyacrylic polymers as retanning agents has become an interesting option but it was necessary to have a better understanding of their retanning behaviour. Along this direction, it has been demonstrated that PCE polyalcohol side chains play a key role in improving the properties of retanned leathers. It has been determined that they are also responsible for improving the dyeing and fatliquoring stages when using acrylic derivatives as retanning agents. PCE retanned leathers are softer and have higher colour intensities than those retanned with linear polyacrylic polymers. The use of PCEs as an alternative to linear polyacrylates as retanning agents avoids using non-environmentally friendly products, making the retanning stage more respectful to the environment. Moreover, the high biodegradability of PCE polymers allows the environmental impact of the retanning stage to be reduced even further and, consequently, the environmental impact of the whole leather making process. All the results obtained in this study easily meet the quality standards of the leather industry and confirm the viability of PCEs as industrial commercial biodegradable retanning agents.

\section{Conflicts of interest}

There are no conflicts to declare.

\section{Acknowledgements}

This work was supported by the Government of Catalonia within the program "Industrial PhD". The authors also want to give a special recognition to the Cromogenia $\mathrm{R} \& \mathrm{D}$ director and colleague, A. Torrelles, who passed away in March 2019 before the publication of this work.

\section{Notes and references}

1 A. D. Covington, Tanning chemistry: The science of leather, Royal Society of Chemistry, Cambridge, 2011.

2 M. Black, M. Canova, S. Rydin, B. M. Scalet, S. Roudier and L. Delgado, Best Available Techniques (BAT) Reference Document 
for the Tanning of Hides and Skins, JRC Reference Reports (European Commission), Luxembourg, 2013.

3 G. Krishnamoorthy, S. Sadulla, P. K. Sehgal and A. B. Mandal, J. Hazard. Mater., 2012, 215-216, 173-182.

4 E. Heidemann, Fundamentals of Leather Manufacturing, Eduard Roether K.G., Darmstadt, 1993.

5 G. C. Jayakuma, A. Mehta, J. R. Rao and N. N. Fathima, RSC Adv., 2015, 5, 31998-32005.

6 K. H. Sizeland, H. C. Wells, S. J. R. Kelly, R. L. Edmonds, N. M. Kirby, A. Hawley, S. T. Mudie, T. M. Ryan and R. G. Haverkamp, RSC Adv., 2017, 7, 40658-40663.

7 S. J. Ali, J. R. Rao and B. U. Nair, Green Chem., 2000, 2, 298-302.

8 J. Matyasovsky, J. Sedliacik, I. Novak, P. Simo, P. Jurkovic, P. Duchovic and A. Kleinova, J. Am. Leather Chem. Assoc., 2016, 111, 358-390.

9 G. D. Pins, D. L. Christiansen, R. Patel and F. H. Silver, Biophys. J., 1997, 73, 2164-2172.

10 A. K. Mondal and P. K. Chattopadhyay, Bangladesh J. Sci. Ind. Res., 2017, 52, 167-176.

11 P. Fratzl, Collagen: Structure and mechanics, Springer US, New York, 2008.

12 Z. Xianglong, I. Yunjun, Z. Qinghua, I. Zhongyu and Z. Xiaoli, J. Soc. Leather Technol. Chem., 2014, 98, 172-176.

13 B. Naviglio, G. Calvanese, G. Tortora, L. Cipollaro and G. Pierri, presented at Stazione Sperimentale per l'industria delle pelli e delle materie concianti, Napoli, 1996.

14 C. Wu, Y. Zeng, X. Liao, W. Zhang and B. Shi, J. Am. Leather Chem. Assoc., 2013, 108, 294-299.

15 M. Sathish, T. S. Bhuvansewari, J. Raghava and N. Nishad, J. Am. Leather Chem. Assoc., 2017, 112, 112-144.

16 Y. Zeng, Y. Song, J. Li, W. Zhang and B. Shi, J. Am. Leather Chem. Assoc., 2016, 111, 398-405.

17 S. V. Kanth, A. Ipe, B. Madhan, R. Venba and A. Dhathathreyan, J. Am. Leather Chem. Assoc., 2007, 102, 135-142.

18 W. C. Prentiss and G. J. Ward, J. Am. Leather Chem. Assoc., 1987, 82, 96-105.

19 D. Sun, Q. He, W. Zhang and B. Shi, J. Soc. Leather Technol. Chem., 2008, 92, 59-64.

20 A. G. Puntener, J. Am. Leather Chem. Assoc., 1996, 91, 287-296.

21 U. Poth, R. Schwalm and M. Schwartz, Acrylic resins, Vincentz Network, Hanover, 2011.

22 W. He, H. Jiang, L. Zhang, Z. Cheng and X. Zhu, Polym. Chem., 2013, 4, 2919-2938.

23 L. Jin, Y. Wang, D. Zhu and Q. Xu, Adv. Mater. Res., 2011, 284-286, 1925-1928.

24 L. Sheng, W. Dequing, L. Zonghui, Z. Shuying and Z. Xinming, J. Am. Leather Chem. Assoc., 1989, 84, 79-85.

25 A. El A'mma, J. Am. Leather Chem. Assoc., 2000, 95, 19-24.

26 J. P. Dix, J. Am. Leather Chem. Assoc., 1998, 93, 283-294.

27 A. El A'mma, J. Am. Leather Chem. Assoc., 1998, 93, 1-15.

28 J. M. Morera, Tanning Technical Chemistry, Igualada Engineering School, Igualada, 2000.

29 S. Dixit, A. Yadav, P. Dwivedi and M. Das, J. Cleaner Prod., 2015, 87, 39-49.
30 C. Canales, A. Rius, A. Avellaneda, E. Monfá, S. Silva, M. Vila, P. Carles, X. Marginet, M. Ferrer and J. Soler, Guide to the best available techniques for the tanning sector in Spain, Technical General Secretariat Publications Centre of the Ministry of Environment, Spain, 2003.

31 European Parliament, Directive 2013/39/UE related to the priority substances in the field of water policy presented in the Official Diary of the European Union L, num. 226, 14.8.2013, pages 1-17, European Parliament, Belgium, August, 2013.

32 J. Buljan, World Leather, 1996, 9, 65-68.

33 X. Guan, J. Chang, Y. Chen and H. Fan, RSC Adv., 2015, 5, 50126-50136.

34 G. Liu, R. Yu, T. Lan, Z. Liu, P. Zhang and R. Liang, RSC Adv., 2019, 9, 27060-27068.

35 D. Petruzzelli, A. Volpe, A. C. Di Pinto and R. Passino, React. Funct. Polym., 2000, 45, 95-107.

36 European Commission, Risk Assessment Report, Joint Research Centre IHCP, UK, 2004.

37 M. Canudas, N. Menna, A. Torrelles, J. de Pablo and J. M. Morera, J. Am. Leather Chem. Assoc., 2019, 114, 80-88.

38 A. Krieg, C. Pietsch, A. Baumgaertel, M. D. Hager, C. R. Becer and U. S. Schubert, Polym. Chem., 2010, 1, 1669-1676.

39 G. Chen, J. Lei, Y. Du, X. Du and X. Chen, Arabian J. Chem., 2017, 11, 747-755.

40 F. Puertas, H. Santos, M. Palacios and S. Martínez-Ramírez, Adv. Chem. Res., 2005, 17, 77-89.

41 E. Sakai, K. Yamada and A. Ohta, J. Adv. Concr. Technol., 2003, 1, 16-25.

42 J. Plank and B. Sachsenhauser, Cem. Concr. Res., 2009, 39, 1-5.

43 I. Navarro-Blasco, M. Pérez-Nicolás, J. M. Fernández, A. Duran, R. Sirera and J. I. Alvarez, Constr. Build. Mater., 2014, 73, 1-12.

44 J. Plank, B. Sachsenhauser and J. de Reese, Cem. Concr. Res., 2010, 40, 699-709.

45 D. Marchon, U. Sulser, A. Eberhardt and R. J. Flatt, Soft Matter, 2013, 9, 10719-10728.

46 D. Tang, X. Jiang, H. Liu, C. Li and Y. Zhao, Polym. Chem., 2014, 5, 4679-4692.

47 K. Yamada, T. Takahashi, S. Hanehara and M. Matsuhisa, Cem. Concr. Res., 2000, 30, 197-207.

48 F. Winnefeld, S. Becker, J. Pakusch and T. Götz, Cem. Concr. Compos., 2007, 29, 251-262.

49 M. Toledano, M. Lorenzo, B. González and S. Seara, Constr. Build. Mater., 2013, 48, 628-635.

50 C. Yuye, W. Xiangxiang, L. Yunjun and Z. Shufen, J. Soc. Leather Technol. Chem., 2010, 94, 200-204.

51 E. Janowska-Renkas, Constr. Build. Mater., 2013, 38, 1204-1210.

52 Y. Song, Y. Zeng, K. Xiao, H. Wu and B. Shi, J. Am. Leather Chem. Assoc., 2017, 112, 128-134.

53 IULTCS official analysis methods for leather, http://www. iultcs.org/pdf/IULTCS-ISO-EN_Leather_test_methods.pdf, accessed April 2019.

54 CLP Legislation, https:/echa.europa.eu/es/regulations/clp/ legislation, accessed January 2019.

55 Organization for Economic Cooperation and Development (OECD), Test No. 301 in Ready Biodegradability - OECD 
Guideline for the Testing of Chemicals, OECD Publishing, Paris, 1992.

56 A. Koochakzaei, H. Ahmadi and M. Mohammadi, J. Am. Leather Chem. Assoc., 2016, 111, 377-382.

57 C. Chahine and C. Rottier, presented in part at 4th Interim Meeting ICOM-CC Working Group on Leather \& Related Materials, Amsterdam, 1995.
58 C.-K. Liu, N. P. Latona and G. L. DiMaio, J. Am. Leather Chem. Assoc., 2002, 97, 355-368.

59 C.-K. Liu and N. P. Latona, J. Am. Leather Chem. Assoc., 2006, 101, 132-139.

60 K. H. Sizeland, H. C. Wells, R. L. Edmonds, N. Kirby and R. G. Haverkamp, J. Am. Leather Chem. Assoc., 2016, 111, 391-426. 